\title{
Nutritional vitamin D status during pregnancy: reasons for concern
}

\author{
Bruce W. Hollis, Carol L. Wagner
}

$\infty \quad$ See related article page $\mathrm{I} 273$

I $\mathrm{n}$ this issue of $C M A J$, Mannion and colleagues ${ }^{1}$ report that women who restricted their intake of milk and vitamin D during pregnancy had smaller babies. In fact, each additional cup of milk per day was associated with a $41-\mathrm{g}$ increase in birth weight; furthermore, each additional daily microgram of vitamin D (of which there are about $2^{1} / 4$ in a cup of milk) was associated with an 11-g increase in infant birth weight. ${ }^{1}$ Specifically, the report deals with the consequences of milk restriction and substandard vitamin D intake during pregnancy, which results in lower infant birth weight. It does not appear that this effect is related to energy or fat intake, although it is possible that decreased protein intake had a role in this observation. The most likely suspect, however, was differing maternal vitamin $\mathrm{D}$ intakes during pregnancy. This is a very intriguing and important observation.

As was recently pointed out in a Cochrane review, ${ }^{2}$ the topic of maternal vitamin D requirements during pregnancy has been poorly studied. The reality is that we do not know what the actual vitamin $\mathrm{D}$ requirement during pregnancy is. For that matter, we do not know the requirement for the general population, either. What we are taught and told is that for a pregnant woman, the adequate intake for vitamin $\mathrm{D}$ (we do not have a dietary recommended intake [DRI] for the vitamin) is 200 IU per day. ${ }^{3}$ What we now know is that this recommended level, which was largely arbitrarily set, will do nothing to improve the nutritional vitamin D status of pregnant women. ${ }^{1,4,5}$

Although vitamin D is undoubtedly important for fetal development and for bone development in childhood, we are beginning to learn that it plays a much wider role in health and disease prevention. It is important to understand that vitamin $\mathrm{D}$ is not really a vitamin; vitamin $\mathrm{D}_{3}$ is a preprohormone made in the skin in response to ultraviolet$\mathrm{B}$ light exposure (Fig. 1). Vitamin $\mathrm{D}_{3}$ is the precursor to form 25-hydroxyvitamin $\mathrm{D}_{3}\left[25(\mathrm{OH}) \mathrm{D}_{3}\right]$, a prehormone, which is ultimately converted to 1,25 -dihydroxyvitamin $\mathrm{D}_{3}$ $\left[1,25(\mathrm{OH})_{2} \mathrm{D}_{3}\right]$. One of the most potent steroid hormones known, $1,25(\mathrm{OH})_{2} \mathrm{D}$ has the capacity to affect many bodily functions beyond calcium metabolism. ${ }^{6}$ If one wants to know one's nutritional vitamin D status, it is $25(\mathrm{OH}) \mathrm{D}$, not $1,25(\mathrm{OH})_{2} \mathrm{D}$, that should be measured.

Circulating $25(\mathrm{OH}) \mathrm{D}$ levels are directly related to dietary vitamin D intake plus skin exposure to ultraviolet light. Conversely, circulating $1,25(\mathrm{OH})_{2} \mathrm{D}$ is controlled largely by calcium homeostasis and is not directly related to one's nutritional vitamin D status. Although the kidney is the endocrine organ known to supply $1,25(\mathrm{OH})_{2} \mathrm{D}$ to the circulation, we are just beginning to understand the importance of the supply of
$25(\mathrm{OH}) \mathrm{D}$ to various tissues (e.g., macrophages, monocytes and prostate tissue) that use $25(\mathrm{OH}) \mathrm{D}$ to produce, in a paracrine-intracrine fashion, $1,25(\mathrm{OH})_{2} \mathrm{D}$ for tissue-specific use. Furthermore, the conversion of $25(\mathrm{OH}) \mathrm{D}$ to $1,25(\mathrm{OH})_{2} \mathrm{D}$ in these tissues appears not to be controlled by calcium, but rather to be directly linked to the substrate availability of $25(\mathrm{OH}) \mathrm{D}$. Thus, this is a complex endocrine system beginning in the largest organ of the body - the skin.

Vitamin D does not occur naturally in foods that humans normally eat. Moreover, the widespread use of sunscreens and public health recommendations to avoid sun exposure reduces dermal synthesis of vitamin $\mathrm{D}_{3}$. Most people therefore get vitamin $\mathrm{D}_{3}$ by taking a vitamin $\mathrm{D}$ supplement or by consuming vitamin $\mathrm{D}$-fortified milk. These sources are nevertheless inadequate and ordinarily fall far short of actual human requirements.

How much vitamin $\mathrm{D}_{3}$ should we be getting? The current recommended amount for adequate intake (200 IU/d for people aged $\leq 50 \mathrm{yr}$ ) was established in $1997 .{ }^{3}$ Before then, the recommended dietary allowance for vitamin $\mathrm{D}$ in infants and children was 400 IU.7 In essence, the scientific basis for this dose was that it approximated that in a teaspoon $(15 \mathrm{~mL})$ of cod liver oil, which had long been considered safe and effective in preventing rickets. ${ }^{8}$ Essentially, these recommendations are all based on a report ${ }^{8}$ issued 4 decades ago by an expert committee on vitamin $\mathrm{D}$ that provided only anecdotal support for what it referred to as "the hypothesis of a small requirement" for vitamin $\mathrm{D}$ in adults. The committee recommended half the 400-IU infant dose to ensure that adults had some oral intake of vitamin $\mathrm{D} .^{8}$

Disturbingly, the basis for these recommendations was made before it was possible to measure circulating $25(\mathrm{OH}) \mathrm{D}$, the true indicator of nutritional vitamin D status. A question that has intrigued our group for years is, How can the recommendation of 200 IU of vitamin D daily apply just as well to a 90-kg adult as a 3.5 -kg term infant? Biologically and pharmacologically, this makes little sense. That amount may be close to what is needed by a baby, but it will not suffice for an adult.

This point is highlighted by recent publications, including 2 publications on vitamin $\mathrm{D}_{3}$ and calcium supplementation and their effects on skeletal protection ${ }^{9}$ and colorectal cancer incidence ${ }^{10}$ in the New England Journal of Medicine as part of the Women's Health Initiative. Although no protective effects of calcium and vitamin $\mathrm{D}_{3}$ supplements were found against those conditions, both studies were seriously flawed. In both arms of the studies, the subjects were already calcium-replete; the treatment group received an additional gram of calcium (for which the recommended dietary allowance is $1.2 \mathrm{~g}$ ). Since 
the study population as a whole already had sufficient nutritional supplies of the mineral, additional calcium did nothing to increase skeletal density: the excess calcium was excreted, and the women in the treatment group manifested a higher incidence of renal stones.

The results were the same among those participating in the colon cancer arm, except for 1 important observation: low circulating baseline $25(\mathrm{OH}) \mathrm{D}$ levels were accompanied by a 2.5-fold increase in the occurrence of colorectal cancer. Daily supplementation with $400 \mathrm{IU}$ of vitamin $\mathrm{D}_{3}$ did not, however, change the incidence. Why? - because the 400 IU-per-day in- tervention did nothing to increase circulating $25(\mathrm{OH}) \mathrm{D}$ concentrations. In other words, these studies do not prove that vitamin $\mathrm{D}_{3}$ supplementation was ineffective in the treatment or prevention of these conditions. Instead, they merely validate the concept that an "adequate intake" fixed at 200 IU per day for adults is irrelevant with respect to maintaining an adequate nutritional vitamin D status. ${ }^{5,11}$

Clearly, we need more information about the amount of vitamin $\mathrm{D}_{3}$ required for human growth, development and health. We are equally ignorant about the possible effects on health of high levels of vitamin $\mathrm{D}_{3}$ : Can we take in too much?

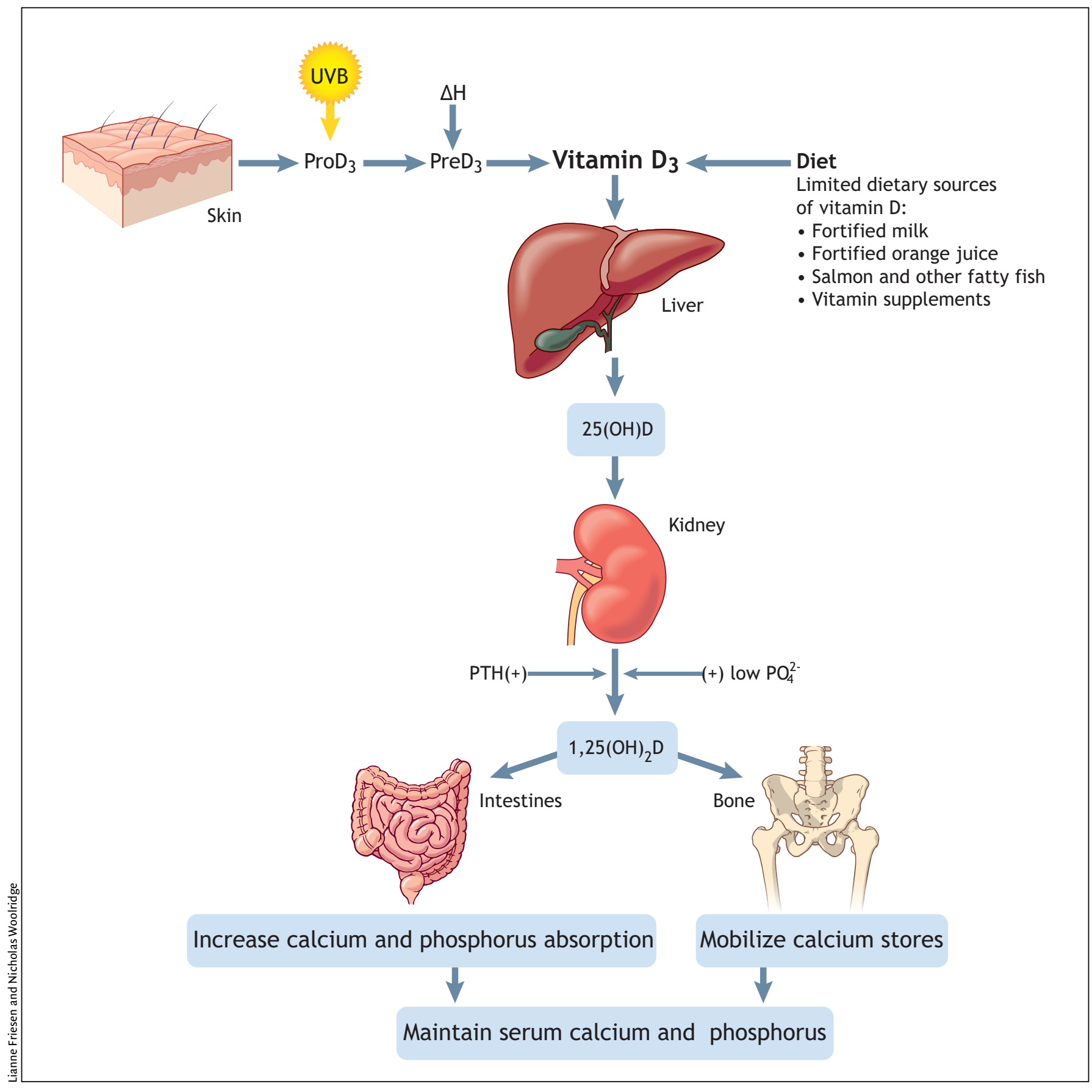

Fig. 1: Production and metabolism of vitamin $\mathrm{D}$ (see text for explanation). UVB = ultraviolet $\mathrm{B}, \mathrm{PTH}=$ parathyroid hormone. 
Vitamin D toxicity, when it occurs, is a serious problem. The first sign is a rise in the ratio of calcium to creatinine in the urine, which precedes hypercalcemia and the problems associated with it. Yet, vitamin D toxicity is rare; its risk has been greatly exaggerated by inappropriate animal studies involving pharmacologic doses of vitamin $\mathrm{D}$ that have no relevance to human physiology. ${ }^{4}$ Heaney and associates ${ }^{12}$ gave people $10000 \mathrm{IU}$ of vitamin $\mathrm{D}_{3}$ daily for 5 months and did not observe a single adverse urinary calcium-creatinine event. Similarly, we have observed no adverse events in our own studies. ${ }^{13-15}$ Despite these and other, more recent studies, ${ }^{13,16,17}$ the upper limit recommended for vitamin $\mathrm{D}_{3}$, termed NOAEL for the "no observed adverse-effect level," remains at $2000 \mathrm{IU}$ per day, ${ }^{3}$ which was based on a scientifically flawed study ${ }^{18}$ that involved few patients. Clearly, this upper limit and the declared adequate intake for vitamin $\mathrm{D}$ must be re-examined and updated to take evidence from more recent scientific studies into account.

How much vitamin $D$, then, is required to meet our adult needs? If we assume that a brief "whole-body" exposure to summer sun generates up to $20000 \mathrm{IU}$ of vitamin $\mathrm{D}_{3}$ for release into the circulation and that this could be our daily requirement, then in the absence of sun exposure a supplement of 200-400 IU per day will be grossly insufficient. ${ }^{16}$ Compared with lightly pigmented people, people whose skin is dark would be especially deficient.

Why should we, as medical practitioners, care about this? We were taught that vitamin D is key only in skeletal integrity and that these skeletal problems, if they occur, can be rapidly corrected by vitamin $\mathrm{D}$ administration. This assumption is wrong and is undoubtedly harmful not only to our patients but also to ourselves. Vitamin D is needed not only for bone metabolism, but also for other systems such as cardiovascular health, neurodevelopment, immunomodulation and the regulation of cell growth, to name but a few of its functions (Fig. 2).

Finally, is there a "normal" circulating $25(\mathrm{OH}) \mathrm{D}$ level in human beings? To properly define such a status, it makes more sense to measure $25(\mathrm{OH}) \mathrm{D}$ concentrations in healthy subjects who are sunbathers, field or construction workers, or other people who work outside without complete cover from clothing and who do not use sunblock. People did not evolve in today's sun-shy culture, so "normal" with respect to circulating $25(\mathrm{OH}) \mathrm{D}$ levels should not be defined by current average or median population levels; it would be like defining "normal" estrogen levels by sampling a population of women of whom half are postmenopausal. By means of biomarkers that are affected by circulating $25(\mathrm{OH}) \mathrm{D}$ (including intact parathyroid hormone, intestinal calcium absorption, skeletal integrity, insulin sensitivity, $\beta$-cell function and, recently, cathelicidin production by macrophages and monocytes), the minimum circulating level of $25(\mathrm{OH}) \mathrm{D}$ has been determined to be $80 \mathrm{nmol}$ ( $32 \mathrm{ng} / \mathrm{mL}$ ). ${ }^{16,19,20}$ To discover whether this level is enough to prevent maladies with long latency (e.g., certain cancers and autoimmune diseases) will require extensive investigation.

The work reported by Mannion and colleagues ${ }^{1}$ demonstrates a likely link between substandard vitamin D intake during pregnancy and decreased birth weight. ${ }^{1}$ Furthermore, the authors observed these effects at relatively modest differences in vitamin $\mathrm{D}$ intake. In our laboratory and clinics, we are studying vitamin D supplementation of up to 4000 IU of

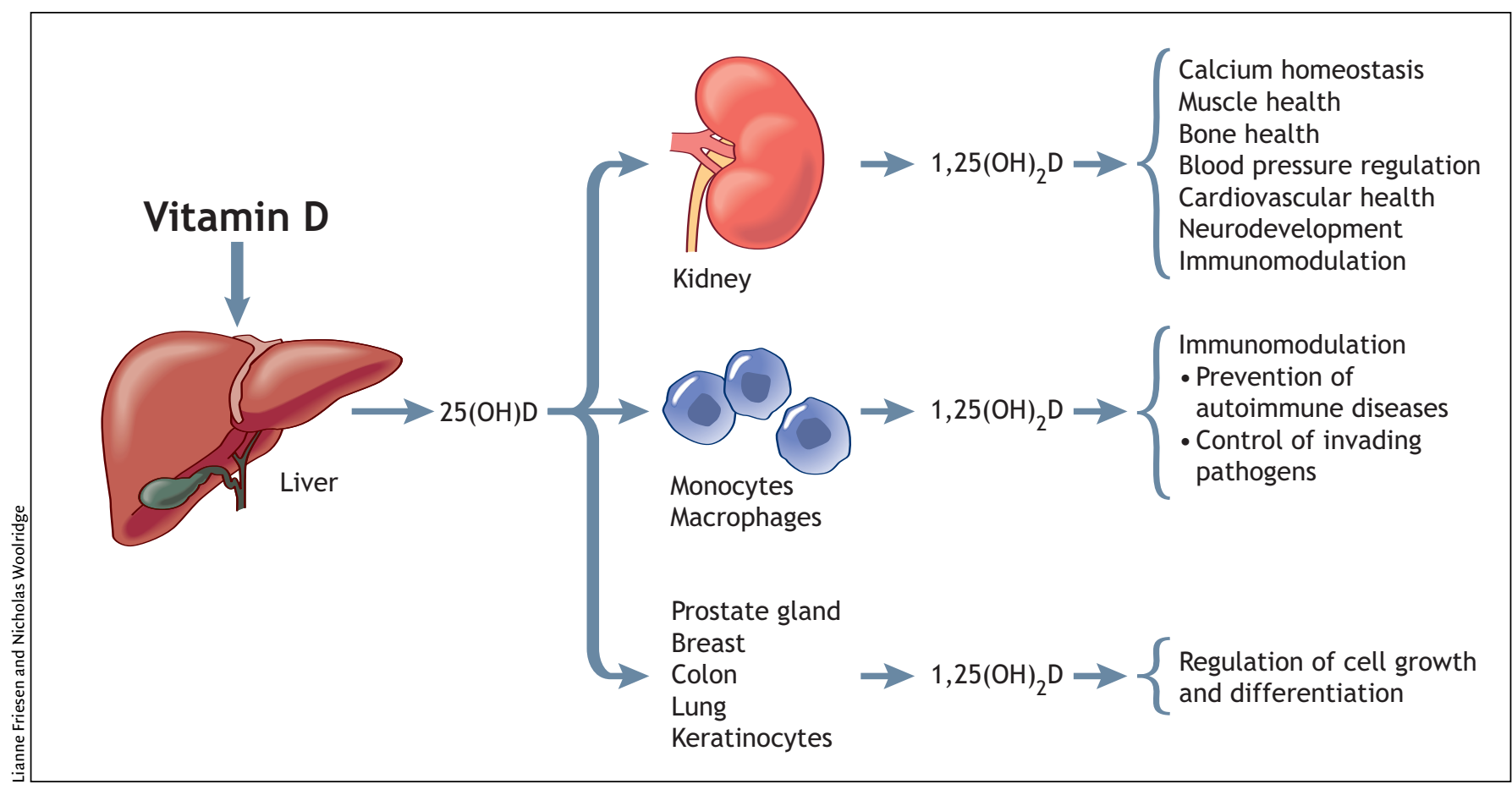

Fig. 2: The endocrine, paracrine and intracrine functions of vitamin $\mathrm{D}$. Vitamin $\mathrm{D}$ is converted in the liver to $25(\mathrm{OH}) \mathrm{D}$, which enters the systemic circulation and is converted to $1,25(\mathrm{OH})_{2} \mathrm{D}$ in a variety of end-organ tissues. As shown, $1,25(\mathrm{OH})_{2} \mathrm{D}$ is involved in the regulation of numerous systems. 
vitamin $\mathrm{D}_{3}$ per day during pregnancy in a multiyear, doubleblinded placebo-controlled trial (http://clinicaltrials.gov \#R01 HD 043921). Unfortunately, our study will not be completed for another $2^{1} / 2$ years. All we can say so far is that some mothers attain a robust nutritional vitamin D status with no observable adverse side-effects.

Why are these studies essential? We believe that they are important to determine the true vitamin $\mathrm{D}$ requirement during pregnancy not only for maternal skeletal preservation and fetal skeletal formation, but also for fetal "imprinting" that may affect neurodevelopment, immune function and chronic disease susceptibility later in life as well as soon after birth. ${ }^{21}$ One need only inspect a recent paper by Javaid and cowork$\mathrm{ers}^{22}$ to appreciate the effect of nutritional vitamin D levels on childhood bone-mineral accrual. The same may be true for the risks of developing autoimmune diseases such as multiple sclerosis (which has recently been linked to seasonality of birth) ${ }^{23}$ and rheumatoid arthritis, ${ }^{24}$ or conditions such as malignancy. ${ }^{25,26}$ Moreover, nutritional vitamin D status has very recently been linked to the human innate immune system and its ability to contain Mycobacterium tuberculosis. ${ }^{20}$ This observation could have profound implications in the treatment of infections.

After all, who would have believed that neural tube defects — initially attributed to season because of low vegetable, and thus folate, intake in winter - could be caused by something so simple? Sometimes, obvious solutions are the most difficult ones to grasp.

Bruce Hollis and Carol Wagner are from the Pediatric Nutritional Sciences, Darby Children's Research Institute, Medical University of South Carolina, Charleston, SC.

Competing interests: None declared for Carol Wagner. Bruce Hollis has received consultancy fees from DiaSor Corporation, Stillwater, Minn.

Contributors: Both authors contributed to drafting, revising and approving the manuscript.

\section{REFERENCES}

1. Mannion CA, Gray-Donald K, Koski KG. Association of low intake of milk and vitamin D during pregnancy with decreased birth weight. CMAJ 2006;174(9):1273-7.

2. Mahomed K, Gulmezoglu AM. Vitamin D supplementation in pregnancy [Cochrane review]. Cochrane Database Syst Rev 2000;(2):CDooo228.

3. Standing Committee on the Scientific Evaluation of Dietary Reference Intakes. Dietary reference intakes for calcium, phosphorus, magnesium, vitamin $D$ and fluoride. Washington: National Academy Press; 1997.
4. Hollis BW, Wagner CL. Assessment of dietary vitamin D requirements during pregnancy and lactation. Am J Clin Nutr 2004;79:717-26.

5. Vieth R, Cole D, Hawker G, et al. Wintertime vitamin D insufficiency is common in young Canadian women, and their vitamin D intake does not prevent it. Eur JClin Nutr 2001:55:1091-7.

6. Pike J, Shevde N. The vitamin D receptor. In: Feldman D, Pike J, Glorieux F, editors. Vitamin D, vol. 1. 2nd ed. San Diego: Elsevier Academic Pres; 2005. p. 167-91.

7. National Academy of Sciences. Recommended dietary allowances. 10th ed. Washington: National Academy Press; 1989.

8. Blumberg RW, Forbes GB, Fraser D. The prophylactic requirement and the toxicity of vitamin D. Pediatrics 1963;31:512-25.

9. Jackson R, LaCroix A, Gass M, et al. Calcium plus vitamin D supplementation and the risk of fractures. N Engl J Med 2006;354(7):669-83

10. Wactawski-Wende J, Kotchen J, Anderson G, et al. Calcium plus vitamin D supplementation and the risk of colorectal cancer. NEngl JMed 2006;354(7):684-06.

11. El-Hajj Fuleihan G, Nabulsi M, Tamim H, et al. Effect of vitamin D replacement on musculoskeletal parameters in school children: a randomized controlled trial. I Clin Endocrinal Metab 2006;91:405-12.

12. Heaney RP, Davies KM, Chen TC, et al. Human serum 25-hydroxycholecalcifero response to extended oral dosing with cholecalciferol [published erratum in Am J Clin Nutr 2003;78:1047]. Am JClin Nutr 2003;77:204-10.

13. Hollis BW, Wagner CL. Vitamin D requirements during lactation: high-dose maternal supplementation as therapy to prevent hypovitaminosis D in both mother and nursing infant. Am J Clin Nutr 2004;80 (Suppl 6):752S-8S.

14. Wagner C, Hulsey T, Fanning D, et al. High dose vitamin $D_{3}$ supplementation in a cohort of breastfeeding mothers and their infants: a six-month follow-up pilot study. Breastfeeding Medicine 2006;1. In press.

15. Basile L, Taylor S, Wagner CL, et al. The effect of high-dose vitamin D supplementation on serum vitamin D levels and milk calcium concentration in lactating women and their infants. Breastfeeding Medicine 2006;1;27-35.

16. Hollis BW. Circulating 25-hydroxyvitamin D levels indicative of vitamin sufficiency: implications for establishing a new effective dietary intake recommendation for vitamin D [review]. J Nutr 2005;135:317-22.

17. Vieth $\mathrm{R}, \mathrm{Chan}$ PC, MacFarlane GD. Efficacy and safety of vitamin $\mathrm{D}_{3}$ intake exceeding the lowest observed adverse effect level. Am J Clin Nutr 2001;73:288-94.

18. Narang N, Gupta R, Jain M, et al. Role of vitamin D in pulmonary tuberculosis $J$ Assoc Physicians India 1984;32:185-6.

19. Chiu K, Chu A, Go V, et al. Hypovitaminosis D is associated with insulin resistance and $\beta$ cell dysfunction. Am J Clin Nutr 2004;79:820-5

20. Liu PT, Stenger S, Li H, et al. Toll-like receptor triggering of a vitamin D-mediated human antimicrobial response. Science DOI: Io.II26/science.II23933. Epub 2006 Feb 23 ahead of print.

21. McGrath J. Does "imprinting" with low prenatal vitamin D contribute to the risk of various adult disorders? Med Hypotheses 2001;56:367-71.

22. Javaid M, Crozier S, Harvey N, et al. Maternal vitamin D status during pregancy and childhood bone mass at 9 years: a longitudinal study. Lancet 2006;367(9504):36-43.

23. Willer CJ, Dyment DA, Sadovnick AD, et al. Timing of birth and risk of multiple sclerosis: population based study. BMJ 2005;330:120. Epub 2004 Dec 7.

24. Merlino L, Curtis J, Mikuls T, et al. Vitamin D intake is inversely associated with rheumatoid arthritis. Arthritis Rheum 2004;50:72-7.

25. Garland C, Comstock G, Garland F, et al. Serum 25-hydroxyvitamin D and colon cancer: eight-year prospective study. Lancet 1989;2 (8673):1176-8.

26. Garland CF, Garland FC, Gorham E, et al. The role of vitamin D in cancer prevention. Am J Public Health 2006;96:25 2-61.

Correspondence to: Dr. Bruce Hollis, Pediatric Nutritional Sciences, Darby Children's Research Institute, Medical University of South Carolina, I73 Ashley Ave., Charleston SC 29425, USA; fax 843 792-I844; hollisb@musc.edu

\section{ACCESS}

$C M A J$ is the only leading general medical journal that is free online. CMAJ.ca receives over 2 million hits per month of which two-thirds are from international readers. 